\title{
Does pleopod setation provide a measure of maturity in female southern rock lobsters Jasus edwardsii?*
}

\author{
CALEB GARDNER, DAVID MILLS and STEWART FRUSHER \\ Tasmanian Aquaculture and Fisheries Institute, University of Tasmania, Private Bag 49, Hobart, Australia, 7000. \\ E-mail: Caleb.Gardner@utas.edu.au
}

\begin{abstract}
SUMMARY: Processes affecting the estimation of the size at onset of maturity (SOM) using ovigerous setae were investigated in southern rock lobsters Jasus edwardsii. Comparison of estimates of SOM based on ovigerous setae in samples collected during summer months (December-March) with those based on the presence of external eggs from winter months (June-August) indicated that ovigerous setae provide an accurate classification of maturity. Females with partially developed setation on pleopods are frequently observed in research catch-sampling projects and their maturity status was unclear. Our results show that these females with partially developed setae are most appropriately classed as immature, based on comparison between estimates of SOM determined by presence of external eggs or setae. The seasonal timing of field sampling affected estimates of SOM based on ovigerous setae, though tag-recapture data indicated that this was not associated with a loss of setae during a second annual moult. Estimates of SOM for populations of Jasus edwardsii around Tasmania can be based on maturity classification using ovigerous setae but care should be taken to ensure that seasonal timing of sampling is consistent.
\end{abstract}

Key words: maturity, rock lobster, Jasus edwardsii, mark-recapture.

RESUMEN: ¿PROPORCIONA LA SETACIÓN DE LOS PLEÓPODOS UN ÍNDICE DE MADUREZ EN HEMBRAS DE LANGOSTA DE TASMANIA, JASUS EDWARDSII? - Los procesos que afectan la estimación de la talla de inicio de madurez (SOM) utilizando sedas ovígeras han sido investigados en la langosta de Tasmania, Jasus edwardsii. La comparación de estimas de SOM basadas en sedas ovígeras en muestras obtenidas durante los meses de verano (diciembre-marzo) con aquellas basadas en la presencia de huevos externos durante los meses de invierno (junio- agosto) indicaron que las sedas ovígeras proporcionan una clasificación acurada de la madurez. Hembras con setación en los pleópodos parcialmente desarrollada son observadas frecuentemente en proyectos de investigación de muestreo de capturas pero la determinación de su estado de madurez no era clara. Nuestros resultados muestran que esas hembras con sedas parcialmente desarrolladas pueden ser consideradas como hembras inmaduras, basándose en la comparación entre las estimas de SOM determinadas por la presencia de huevos externos o de sedas. La selección del momento de muestreo de campo en relación con la estacionalidad afecta las estimas de SOM basadas en sedas ovígeras, no obstante, datos de marcado y recaptura indicaron que ello no estaba asociado con una pérdida de sedas durante una segunda muda anual. Estimas de SOM para poblaciones de Jasus edwardsii alrededor de Tasmania pueden ser basadas en la clasificación de madurez mediante sedas ovígeras, pero debe tenerse en cuenta que la realización estacional del muestreo de campo sea consistente.

Palabras clave: madurez, langosta, Jasus edwardsii, marcado-recaptura.

\section{INTRODUCTION}

The size at onset of maturity (SOM) of female lobsters is an important parameter for lobster fisheries

*Received March 1, 2004. Accepted July 1, 2004. worldwide as it influences management through size limits and targets for egg production. Size at onset of maturity in lobsters is usually quantified by a logistic curve that spans the transition from small immature animals to large mature animals. In this process of modelling maturity, observations are taken from the 
population of interest with individuals classed as either mature or immature.

The classification of female lobsters as mature can be made on the basis of several characters, including ovarian development, the presence of external eggs, endopodite processes of pleopods bearing ovigerous setae, sperm within seminal receptacles or spermatophore (tar spot), and the morphometry of the abdomen, legs or pleopod exopodite (Krouse, 1973; Plaut, 1993; Hobday and Ryan, 1997; Minagawa and Sano, 1997). Size at onset of maturity in Jasus species is most often based on observations of the endopodite of pleopods-where ovigerous setae are well developed the animals are classed as mature (e.g. Booth, 1984; Cockcroft and Goosen, 1995; Hobday and Ryan, 1997). This measure of maturity is related to the need for setae for egg attachment after extrusion, so there is an expectation that females without setose endopodites would be unable to successfully brood eggs.

One of the reasons why many researchers favour determining SOM on the basis of ovigerous setae is that samples can be collected throughout the year, rather than only during the egg-bearing season. Sampling females while they are ovigerous can be logistically difficult for many lobster species due to reduced catchability (Ziegler et al., 2002a). In addition, maturity data is normally collected as part of larger catch sampling exercises that are not targeted to this specific issue; the use of a secondary indicator of maturity such as pleopod setation enables data to be collected throughout the year. For these reasons, the system of classification of maturity based on ovigerous setae is used by many biologists although, as noted by MacDiarmid (1989a), this carries assumptions that are seldom considered.

This paper examines several of these assumptions in the use of pleopod setation for classifying the maturity status of southern rock lobsters Jasus edwardsii around Tasmania, Australia. Female lobsters in these populations produce a single egg clutch annually. Egg extrusion usually occurs in April-May and eggs hatch in September-October. For most of Tasmania, females above the size that is routinely tagged (80 $\mathrm{mm}$ carapace length) only moult once per annum, just before egg extrusion, although in northern areas a second moult can occur (Fielder and Olsen, 1967).

We examined several issues related to classifying maturity based on the setation of pleopods. First, females often pass through a transitional stage between non-setose and setose categories in which the pleopods have developed setation but much less than a typical "setose" female. These animals have been classed as "partially-setose" in historical records and we tested whether they are more appropriately classed as immature or mature. Secondly, we tested whether setose state was a valid indirect measure of maturity. This was done by contrasting estimates of SOM from data of setose state with estimates of SOM based on ovigerous state data collected during the winter months when eggs are brooded. An associated issue was the potential for females to alter their setose by moults through the year, that is, to revert back to a non-setose state during the non-breeding season. Data for SOM estimation based on pleopod setation are often collected throughout the year, so we examined the potential for the timing of sampling seasonally to affect estimates of SOM. Lastly, we assessed the use of pleopod setation as a basis for tracking onset of maturity in tagged animals.

\section{METHODS}

\section{Sample sites and specimen collection}

Data for this research were drawn from historical records of catch sampling around Tasmania from 1963 to 2002. Females were collected in baited traps set from commercial and research vessels and their size was recorded as carapace length (CL, the distance from the base of the antennal platform to the dorsal, posterior margin of the carapace along the midline). Data were collected for general stock assessment purposes rather than research targeted at collecting maturity data. The research presented here focuses on sites where repeated samples were collected, especially for assessing seasonal trends. Two sites were selected for analysis of data on a month-by-month basis: a northern site, Porkies Break, which is off western King Island and the Crayfish Point MPA in the south (Fig. 1). Extremes of growth are known to occur at these sites, with most animals at the Porkies Break site moulting twice per year while females at the Crayfish Point site usually only moult annually (Fielder and Olsen, 1967). Broader time steps of comparison in data between periods when females are ovigerous/nonovigerous were investigated in data from a further 10 sites (Sandstone Bluff, Port Davey, Maatsuyker Island, The Friars, Cataraqui Point, Ille de Gulf, 


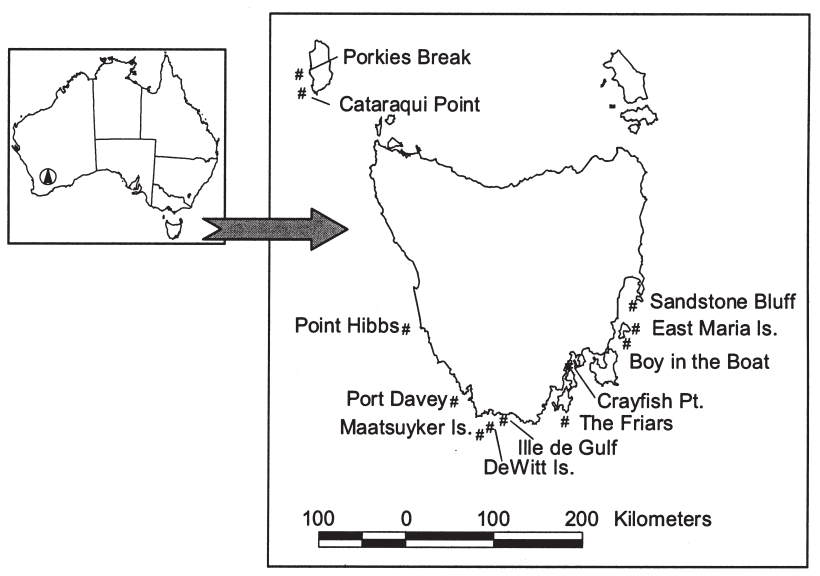

FIG. 1. - Sample sites for examination of maturity.

Point Hibbs, DeWitt Island, East Maria Island and Boy in the Boat).

Individual animals were tracked through time using individually coded T-bar tags (Hallprint ${ }^{\mathrm{TM}}$ ) inserted ventrally into the abdomen.

Females were classified as mature based on the development of setae on the endopodite of pleopods. In some cases, slight development of setae was observed and these animals were classed as "partially setose".

\section{Contrasting SOM estimates based on presence of ovigerous setae with those based on presence of external eggs}

Samples collected during winter months included ovigerous females, that is, animals in which maturity could be observed directly, rather than inferred from the development of ovigerous setae. Samples collected from June to August were used to estimate SOM based on presence or absence of external eggs. These estimates were compared with estimates from the same sites based on ovigerous setae in samples collected from December to March, which is outside the egg-bearing season. Data for these analyses were collected between 1992 and 2002 and pooled across years. Effort was made to collect subsequent surveys at the same location for each survey by deploying traps within defined quadrangles or by attempting to reset traps precisely on GPS marks.

\section{Monthly/seasonal patterns in SOM estimates}

We investigated the potential for the seasonal timing of sampling to influence estimates of SOM using three different approaches. First, we examined the incidence of animals reverting back to a nonsetose state from a setose state following the release of larvae in late Spring (Booth, 1984; MacDiarmid, 1989a). This was examined using the tag recapture history of individual animals from Porkies Break (NW) and Crayfish Point (SE); did any animals change from mature to immature as classified by setal development? Secondly, we determined SOM based on setal development from multiple separate monthly samples from these two sites and examined temporal variation. Thirdly, the seasonal timing of transition from non-setose to setose was examined from tag-recapture data from Crayfish Point, Boy in the Boat and Sandstone Bluff. Data from these sites were combined to increase the sample size of lobsters that were released as non-setose females and recaptured as setose females. A total of 496 recaptures fitted these criteria. Surveys at Crayfish Point included two periods of regular samples each month, one for a period of 6 months, the other for 16 months, which were especially useful for investigating seasonal timing of transition from non-setose to setose. Sample periods were condensed into bimonthly groups giving a maximum of 6 surveys per annum. Lobsters that were released in each of the 6 possible bimonthly sample periods were combined for different years. For example, lobsters released in the sample period of February/March in 1997 and 1999 were treated as a unit. This increased the sample size, but was based on the untested assumption that the timing of transition from nonsetose to setose does not vary between years. Recaptures taken more than 28 months after the first release survey were excluded as these tended to consist of multiple recaptures of females that had become setose much earlier, and thus were of little value for determining seasonal timing of transition from non-setose to setose.

\section{Statistical analyses}

Carapace length (CL) was used to scale female size in all analyses. We modelled the proportion of females that were mature $(\mathrm{P})$ at a given $\mathrm{CL}(\mathrm{X})$, based on presence or absence of setae or eggs for each site with a logistic function of the form: $P=$

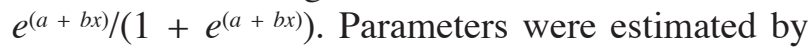
maximising the Log likelihood derived from the logit transformation (Neter et al., 1990). These models were then used to estimate the size at which 50 and $95 \%$ of the population were mature (L50\% and 
L95\%). Estimation of uncertainty around these estimates followed the method of Turner et al. (2002). Ninety five percent confidence limits around model fits were estimated from 1000 simulations for each area in a bootstrapping routine in which data were randomly sampled with replacement from each of the $3 \mathrm{~mm}$ size categories (Haddon, 2001). The middle $95 \%$ of the bootstrap replicates constituted the confidence interval. Confidence limits derived by this method reflect the uneven distribution of certainty around estimates of SOM. Less certainty was observed towards the lower bound due to the smaller sample sizes of individuals classed as immature rather than mature.

Analyses of SOM were conducted only when sample sizes were $>90$ individuals. This limit appeared acceptable for samples from northern areas, where immature animals were well represented in samples, but some of the samples from southern sites contained few immature animals due to their slower growth rates and the selectivity of the traps used for sampling. Hence, despite large samples of several hundred animals, model fits were occasionally poor as samples contained mainly mature females. Those analyses were excluded from the results presented here.

Recapture histories from trapping surveys were analysed to determine the seasonal timing of transition from non-setose to setose using ArnasonSchwartz (AS) tag/recapture models (Arnason, 1973; Schwartz et al., 1993), a multistate generalisation of Cormack-Jolly-Seber (CJS) models (Cormack, 1964; Jolly, 1965; Seber, 1965). These multistate models provide increased model flexibility by allowing animals to transit from one state to another, for example between spatial areas or between levels of maturity as in this application (Brownie $e t$ al., 1993). Models were fitted using the program MARK (White and Burnham, 1999).

We estimated survival and resighting probabilities for each survey and the probability of lobsters changing from immature to mature in the period between consecutive surveys. The fully parameterised (saturated) AS model can be represented by $\phi(t s) \rho(t s) \psi(t s)$. That is, the likelihoods of survival $(\phi)$, resighting $(\rho)$ and maturity transition $(\psi)$ are a function of time of survey $(\mathrm{t})$ and state $(\mathrm{s}=$ lobster with or without setae). Here, with 14 bi-monthly time periods and 2 states (setose and non-setose), the unconstrained saturated model has 84 parameters or $28(2 \times 14)$ parameters for each of $\phi, \rho$ and $\psi$. All models were initially structured using the identi- ty design matrix and sin link function, as this provided meaningful estimates for the greatest number of parameters.

Model fitting commenced with a reduced model that set parameters for the transition from setose to non-setose to zero. A series of reduced models were chosen a priori to test feasible hypotheses that could simplify the model and thus increase precision in estimation of the transition parameters that were of interest (Lebreton et al., 1992). Normalised Quasilikelihood Akaike's Information Criterion weights, corrected for over-dispersion (QAICc), were used to determine the more parsimonious option when choosing whether to accept or reject hypotheses.

\section{RESULTS}

\section{Contrasting SOM estimates based on presence of ovigerous setae with those based on presence of external eggs}

Estimates of SOM based on presence and absence of ovigerous setae on pleopods in summer provided similar estimates of SOM as determined by the presence or absence of eggs in winter for most sites (Fig. 2). Estimates were significantly different $(\mathrm{P}<0.05)$ at 2 sites only, Cataraqui Point in the far north and DeWitt Island in the far south. The maturity estimates based on berried vs non-berried was significantly greater than that derived from setal observations at Cataraqui Point, while the reverse was true at DeWitt Island. Few animals were classed as "partially-setose" so the inclusion or exclusion of these animals from the category of "immature" in analyses based on ovigerous setae had little impact on estimates of maturity at all sites except Port Davey. The classification of numerous animals as "partially setose" at Port Davey led to an apparent under-estimate of SOM when these animals were considered to be "mature".

\section{Bias in SOM estimates through loss of ovigerous setae}

At both sites, a small proportion of those animals with ovigerous setae on release were subsequently recaptured and recorded without ovigerous setae or only partially setose (14 of 1499 or $0.9 \%$ at Crayfish Point and 30 of 2143 or $1.4 \%$ at Porkies Break).

Of the 44 animals from both sites where a change from setose to non-setose was recorded, 14 were 


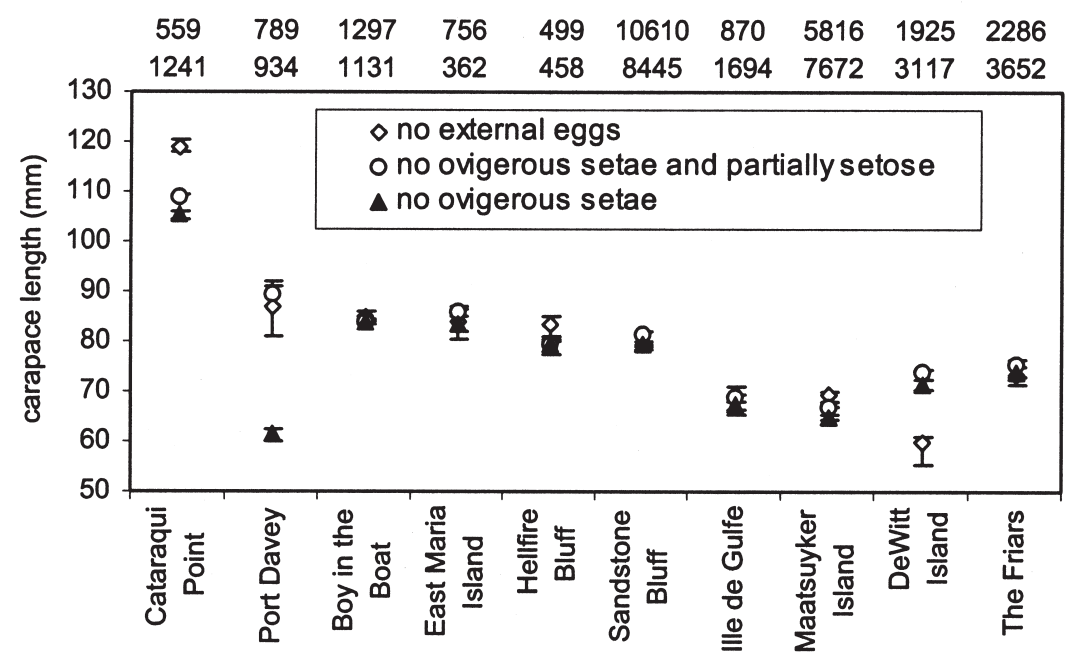

FIG. 2. - Estimates of L50\% (+/- 95\% confidence limits) from nine Tasmanian sites where the immature category was based on either: (i) lack of external eggs (June-August only); (ii) no ovigerous setae (December to March only); or (iii) no ovigerous setae or animals classed as "partially developed" with sparse ovigerous setae (December to March only.) Sample sizes for each analysis is shown with external egg samples upper and setose samples lower.
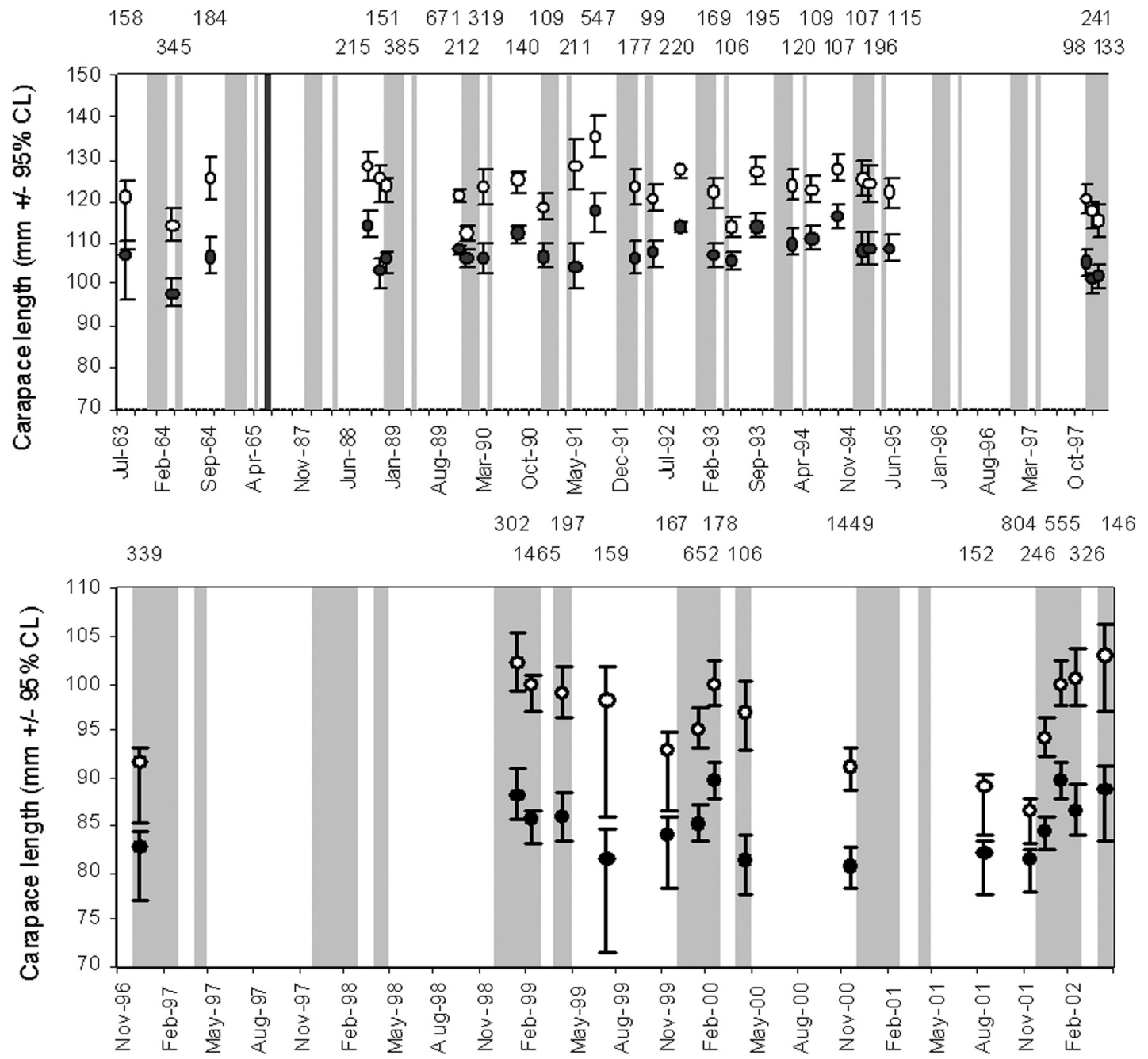

FIG. 3. - Estimates of L50\% (solid points) and L95\% (hollow points) SOM (+/- 95\% confidence limits) from monthly samples taken at Porkies Break (upper) and Crayfish Point (lower). Maturity was based on the presence/absence of ovigerous setae with "partially setose" females considered immature. Shaded areas represent summer (broad band) and the month when most females moult (April, narrow band). Note that the time scale for the Porkies Break series is discontinuous. Sample sizes are shown above each point. 

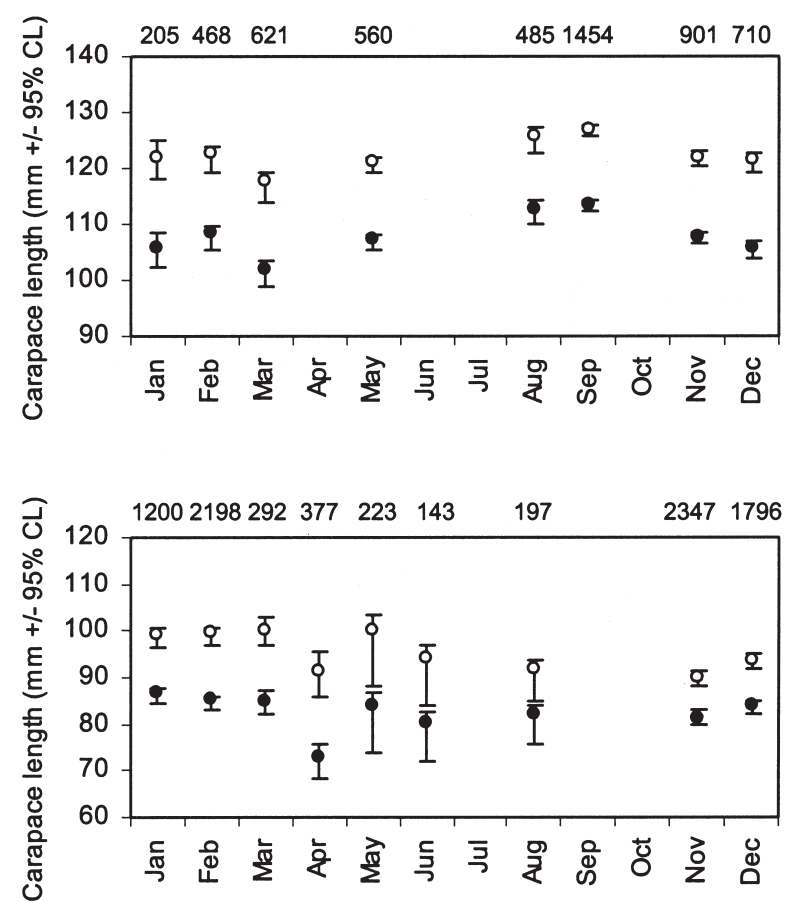

FIG. 4. - Estimates of L50\% (solid points) and L95\% (hollow points) SOM (+/- 95\% confidence limits) from monthly samples pooled across years taken at Porkies Break (upper) and Crayfish Point (lower). Maturity was based on the presence/absence of setae with "partially setose" females considered immature. Sample sizes are shown above each point.

identified as data recording errors (because they were recaptured within the same month without changing size and were classed as setose). Of the remaining 30 animals, only 5 were recaptured below the $95 \%$ SOM for the site, as estimated by presence of external eggs $(96 \mathrm{~mm}$ and $125 \mathrm{~mm} \mathrm{CL}$ at Crayfish Point and Porkies Break respectively). This indicates that few of the animals in which a change from setose to non-setose was recorded were likely to be first-year breeders.

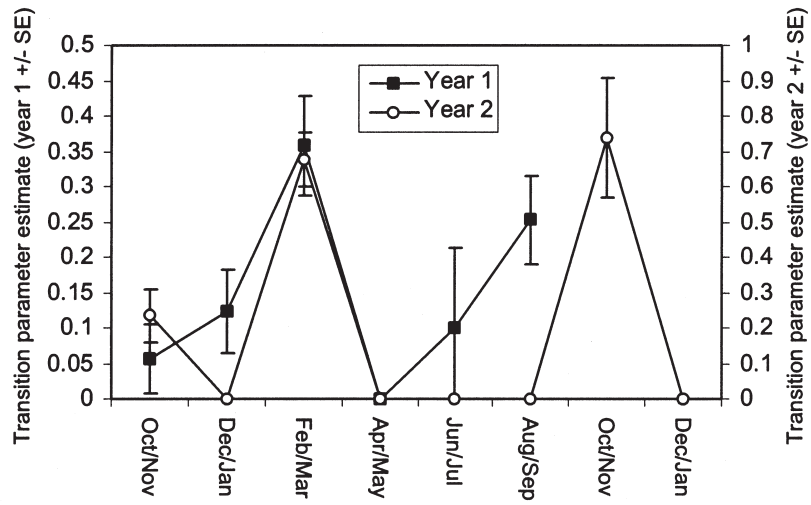

FIG. 5. - Probability ( $\pm 1 \mathrm{SE}$ ) of female lobsters transiting from nonsetose to setose. Actual probability estimates are biased as the proportion of females yet to transit is lower for year 2 than for year 1 ; however, relative magnitude of parameter estimates indicate seasonal trends.

\section{Seasonal patterns in SOM estimates}

Monthly estimates of SOM from Crayfish Point and Porkies Break varied significantly from month to month, although generally without any clear trend (Fig. 3). When data from different years were pooled (Fig. 4), the month with lowest estimated $\mathrm{SOM}$ at both sites was around the time of reduced catchability associated with mating and egg extrusion (March-May; Ziegler et al., 2002a). Estimates from Porkies Break were highest during September, which is around the time of larval release from females. Unfortunately, no estimates from Crayfish Point were available from this period.

The Arnason-Schwartz (AS) tag/recapture model used to examine the seasonal timing of transition of female lobsters from non-setose to setose was reduced through examination of a series of hypotheses. It appeared that survival was constant between survey periods but that separate parameters were required for setose and non-setose females. Making resighting probability equivalent for both setose and non-setose females increased the parsimony of the model. The effect of making resighting probability equivalent for surveys was not evaluated because it was known that effort (pot lifts) varied between surveys. The hypothesis that timing of transition from non-setose to setose was constant throughout the year was tested and rejected by using a single parameter rather than separate parameters for each survey. Lastly, we attempted to improve estimates of parameters describing transition to setose state for each bimonthly period by using a single parameter for all matching periods - for example, by using a single parameter for all transitions between December/January and February/March. This reduced the number of transition parameters to 6 . However, this model was found to be less parsimonious than a model with a transition parameter between each survey period. Parameter estimates for the transition from non-setose to setose state appeared to have two seasonal peaks, one prior to April May when egg extrusion occurs and another separated by around six months in the period between September and December (Fig. 5).

\section{DISCUSSION}

Several researchers have previously differentiated between "size at onset of maturity" (SOM) and "size at onset of breeding" (SOB) in Jasus species (e.g. Silberbauer, 1971; Booth, 1984; Montgomery, 
1992; Hobday and Ryan, 1997). SOM estimates were based on the presence of ovigerous setae while SOB estimates were based on the presence of external eggs during the brooding period. This separation recognised that the presence or absence of ovigerous setae on the endopodite of pleopods may not necessarily reflect the maturity status of the individual. Estimates of these two measures in this study were not significantly different at most sites, which suggests that they are equivalent. Although differences were observed at DeWitt Island and Cataraqui Point, the lack of consistency indicates that there is no systematic bias from the use of ovigerous setae as an indicator of maturity. This result supports current assessments of several Jasus fisheries where management of egg production is driven by estimates of SOM based on presence of ovigerous setae (e.g. Punt and Kennedy, 1997; Hobday and Punt, 2001)

Booth (1984) observed a much smaller SOM based on ovigerous setae than SOB based on external eggs in New Zealand populations of Sagimarius verreauxi (synonim of Jasus verreauxi). This difference was attributed to the development of ovigerous setae prior to the development of functional maturity. In contrast, Montgomery (1992) observed no significant difference in these measures in populations of the same species off the coast of New South Wales, Australia. These opposing results illustrate the importance of quantifying the error around point estimates of SOM if comparisons are made, such as between sites or between different criteria for defining maturity. Montgomery (1992) also considered that the classification of females as immature based on setose state carries an element of subjectivity and that this introduces a risk of different results between studies.

We observed an element of subjectivity in classification of individuals as "partially setose" by at-sea observers. This classification appeared to result from low level development of setae and uncertainty on the part of the observer. The classification of individual lobsters as "partially setose" in the context of maturity is of little value-clearly the individual should fall into the categories of immature and mature. At most sites, very few animals were classed as "partially setose" and there was no significant difference between estimates of SOM whether these animals were treated as immature or mature. However, samples from Port Davey contained a large number of records of "partially setose" animals and SOM estimates were biased lower by over $20 \mathrm{~mm} \mathrm{CL}$ when these animals were considered mature. Although this problem of uncertainty in classification of setose state was not widespread in our data set, it had the potential to incorrectly lower estimated SOM in the Port Davey region. The Tasmanian regional stock assessment model developed by Punt and Kennedy (1997) would consequently overestimate total egg production in this area, where the minimum legal size of $105 \mathrm{~mm} \mathrm{CL}$ is much larger than the estimated SOM.

MacDiarmid (1989a) suggested that the timing of sampling might bias estimates of SOM where animals are classified as mature on the basis of ovigerous setae. Possible seasonal biases include interactions between maturity, size, movement, catchability and also the periodic loss of setae. A seasonal loss of setae was reported by MacDiarmid (1989b) from a reserve in north eastern New Zealand, where around $3 \%$ of tagged females in summer moulted to a non-setose state. We investigated the potential for this bias to occur in Tasmania but found no conclusive evidence. Few recaptured females appeared to have lost ovigerous setae and most of these were clearly the result of recording errors. In addition, most records were for animals well above L95\% rather than around the SOM, as per MacDiarmid's (1989b) observations.

Although there was no evidence for a seasonal loss of setae, other seasonal processes did appear to affect estimates of SOM. Estimates from both Porkies Break and Cataraqui Point were often significantly different between months and of a magnitude that would be expected to influence management of egg production. Estimates of SOM appeared to show trends across months, especially at Porkies Break, which indicates that a seasonal process was influencing results, rather than just random variation in estimates. The nature of this process is unclear, as there was little similarity in trends between the two sites, except that SOM estimates from both sites were lowest around March/April, immediately prior to the main annual female moult (Fielder and Olsen, 1967). This suggests that some process that influences the composition of catches is also influencing estimates of SOM, such as movement or catchability, both of which vary seasonally and in relation to maturity of females (Gardner et al., 2003; Ziegler et al., 2002a). MacDiarmid (1989b) found that larger females tend to moult before smaller females, which could also influence the composition of catches taken during this period.

The moult from non-setose to setose state occurred in pulses during the year and this may pro- 
duce seasonal variation in estimates of SOM. Our analysis of tag-recapture data from southern sites shows that a peak in the transition or moult to maturity, based on setal development, occurs prior to the main period of egg extrusion in April/May. In southern areas this period is also the time of the single annual moult of mature females (Ziegler et al., 2002a). A second period of moulting, around 6 months later between September and December, resulted in a smaller proportion of immature, nonsetose females moulting and becoming setose.

Regardless of the source of the variation in estimates of SOM between months, these observations have a repercussion for sample design; where the aim of sampling to estimate SOM is to compare between treatments such as site or density, the seasonal timing of sampling has the potential to bias results. Thus, different samples should ideally be taken during the same seasonal period and avoiding times of the major biological events of moulting, mating and larval release. This simple observation is important for fisheries research on rock lobsters as SOM is typically estimated from data collected throughout the year as part of catch sampling programs. Analyses that use data from a range of seasons and assume no seasonal effect have been used as evidence of spatial and temporal differences in SOM (Annala et al., 1980; Polovina, 1989). This risk of seasonal variation in SOM biasing conclusions has recently been addressed in the development of protocols for estimating SOM in clawed lobsters (DFO Canada, 2003), and a similar need for consistent timing in data collection appears to exist for spiny lobsters.

The potential flaws in classifying maturity by ovigerous setae has prompted other researchers to explore alternative methods, although these typically have their own biases or flaws. Even the use of presence or absence of external eggs can produce misleading results, as a portion of the mature population can be found without eggs during the peak egg-bearing period. This can be caused by failure to mate (MacDiarmid and Butler, 1999) or simply asynchrony in timing of extrusion, which is more common in tropical species (Briones-Fourzan and Lozano-Alvarez, 1992). The process of fitting a logistic curve to data such as these, in which the upper bound of $100 \%$ is never reached, usually involves scaling proportions to an upper limit, which is chosen subjectively (King, 1995).

Measurement of ovarian development (e.g. Annala et al., 1980) allows maturity to be estab- lished with certainty and is not affected by the ability of the female to successfully mate and produce external eggs. However, this method is time-consuming and destructive, and female size is recorded prior to the winter moult and egg extrusion (in Jasus species in which egg extrusion is shortly after moulting; MacDiarmid, 1989a). Booth (1984) investigated the use of tag-recapture data to estimate the size at transition to maturity in $S$. verreauxi. His analysis used data from females that were immature when released but mature when recaptured. In $J$. edwardsii, this method tends to be biased towards larger SOM because early maturing females are excluded from the original sample of animals that were tagged and released due to reduced catchability (Ziegler et al., 2002b). In addition, small mature females are excluded from the analysis if captured for the first time. Multi-state tagging models are suitable for dealing with the transition to maturity and could overcome this bias by including all tagging data (White and Burnham, 1999), although models dealing with the covariate of size both before and after the transition to maturity are presently unavailable.

In summary, single-observation samples of female Jasus edwardsii in which the maturity state is categorised on the basis of ovigerous setae appear to provide robust estimates of SOM, which supports the use of these data in existing fisheries assessment models. In Tasmania, the incidence of female Jasus edwardsii losing ovigerous setae during a summer moult appears to be negligible and unlikely to influence estimates of SOM. Although seasonal variation in SOM is often assumed to be negligible, we show that the magnitude of this variation can be large. Extreme estimates of SOM from different months varied by over $10 \mathrm{~mm} \mathrm{CL}$, which is large relative to alternate minimum size limits considered for management of $J$. edwardsii egg production. Timing in collection of samples should be consistent between years and avoid periods of biological activity, such as moulting, to minimise bias of management decisions based on SOM, such as minimum size limits to protect egg production.

\section{ACKNOWLEDGEMENTS}

Malcolm Haddon assisted with the likelihood estimation of SOM parameters. The analyses presented in this paper relied on extensive data sets collected by numerous people over several decades. 
CSIRO scientists collected data from Porkies Break during the 1960s. Especially important contributions since 1989 were made by Jac Gibson, Matt Francis, Andrew Cawthorn, Rod Pearn, Craig Mackinnon, Philippe Ziegler, Sam Ibbott, Pip Cohen and Steve Bishop.

\section{REFERENCES}

Annala, J.H., J.L. McKoy, J.D. Booth and R.B. Pike. - 1980. Size at the onset of sexual maturity in female Jasus edwardsii (Decapoda: Palinuridae) in New Zealand. N.Z. J. Mar. Freshwat. Res., 14: 217-227.

Arnason, A.N. - 1973. The estimation of population size, migration rates and survival in a stratified population. Res. Popul. Ecol., 15: $1-8$.

Booth, J.D. - 1984. Size at onset of breeding in female Jasus ver reauxi (Decapoda: Palinuridae) in New Zealand. N.Z. J. Mar. Freshwat. Res., 18: 159-169.

Briones-Fourzan, P. and E. Lozano-Alvarez. - 1992. Aspects of the reproduction of Panulirus inflatus (Bouvier) and $P$. gracilis Streets (Decapoda:Palinuridae) from the Pacific Coast of Mexico. J. Crust. Biol., 12: 41-50.

Brownie, C., E. J. Hines, J. D. Nichols, K.H. Pollock and J.B. Hestbeck. - 1993. Capture-recapture studies for multiple strata including non-Markovian transitions. Biometrics, 49: 11731187.

Cockcroft, A.C. and P.C. Goosen. - 1995. Shrinkage at moulting in the rock lobster Jasus lalandii and associated changes in reproductive parameters. S. Afr. J. mar. Sci., 16: 195-203.

Cormack, R.M. - 1964. Estimates of survival from the sighting of marked animals. Biometrika, 51: 429-438.

Department of Fisheries and Oceans, Canada. - 2003. Workshop on lobster (Homarus americanus and H. gammarus) reference points for fishery management held in Tracadie-Sheila, New Brunswick, 8-10 September 2003. M. Comeau (ed.). Can. Tech. Rep. Fish. Aquat. Sci., 2506, pp. 46.

Fielder, D.R. and A.M. Olsen. - 1967. Synopsis of biological data on the southern spiny lobster Jasus lalandei (H. Milne Edwards) 1837. Australian and New Zealand Meeting on Decapod Crustacea, 24-28 October, Sydney 1967. pp. 2614-2664.

Gardner, C., S. Frusher, M. Haddon and C. Buxton. - 2003. Movements of the southern rock lobster Jasus edwardsii in Tasmania, Australia. Bull. Mar. Sci., 73: 653-671.

Haddon, M. - 2001. Modelling and Quantitative Methods in Fisheries. Chapman and Hall, London.

Hobday, D. and A.E. Punt. - 2001. Size-structured population modelling and risk assessment of the Victorian southern rock lobster, Jasus edwardsii, fishery. Mar. Freshwat. Res., 52: 14951507.

Hobday, D.K. and T.J. Ryan. - 1997. Contrasting sizes at sexual maturity of southern rock lobsters (Jasus edwardsii) in the two Victorian fishing zones: implications for total egg production and management. Mar. Freshwat. Res., 48: 1009-1014.

Jolly, G.M. - 1965. Explicit estimates from capture-recapture data with both death and immigration-stochastic model. Biometrika, 52: 225-247.

King, M. - 1995. Fisheries biology, assessment and management Blackwell, Melbourne.

Krouse, J.S. - 1973. Maturity, sex ratio, and size composition of the natural population of American lobster, Homarus americanus, along the Maine coast. Fish. Bull., 71: 165-173.

Lebreton, J.D., K.P. Burnham, J. Clobert and D.R. Anderson. 1992. Modelling survival and testing biological hypothesis using marked animals: a unified approach with case studies. Ecol. Monogr., 62: 67-118.

MacDiarmid, A.B. - 1989a. Size at onset of maturity and sizedependent reproductive output of female and male spiny lobsters, Jasus edwardsii (Hutton) (Decapoda, Palinuridae). J. exp. mar. Biol. Ecol., 127: 229-243.

MacDiarmid, A.B. - 1989b. Moulting and reproduction of the spiny lobster Jasus edwardsii (Decapoda: Palinuridae) in northern New Zealand. Mar. Biol., 103: 303-310.

MacDiarmid, A. B. and M.J. IV. Butler. - 1999. Sperm economy and limitation in spiny lobsters. Behav. Ecol. Sociobiol., 46: 14-24.

Minagawa, M. and M. Sano. - 1997. Oogenesis and ovarian development cycle of the spiny lobster Panulirus japonicus (Decapoda: Palinuridae). Mar. Freshwat. Res., 48: 875-887.

Montgomery, S.S. - 1992. Sizes at first maturity and at onset of breeding in female Jasus verreauxi (Decapoda: Palinuridae) from New South Wales waters, Australia. Aust. J. Mar. Freshwat. Res., 43: 1373-1379.

Neter, J., M.H. Kutner, C.J. Nachtsheim and W. Wasserman. - 1990. Applied Linear Statistical Models. 4th Ed. Irwin, Chicago.

Plaut, I. - 1993. Sexual maturity, reproductive season and fecundity of the spiny lobster Panulirus penicillatus from the Gulf of Eilat (Aqaba), Red Sea. Aust. J. Mar. Freshwat. Res., 44: 527-535.

Polovina, J.J. - 1989. Density dependence in spiny lobster, Panulirus marginatus, in the northwestern Hawaiian Islands. Can. J. Fish. Aquat. Sci., 46: 660-665.

Punt, A.E. and R.B. Kennedy. - 1997. Population modelling of Tasmanian rock lobster, Jasus edwardsii, resources. Mar. Freshwat. Res., 48: 967-980.

Schwartz, C.J., J.F. Schweigert and A.N. Arnason. - 1993. Estimating migration rates using tag-recovery data. Biometrics, 49: 177-193.

Seber, J.A.F. - 1965. A note on the multiple recapture census. Biometrika, 52: 249-259.

Silberbauer, B.I. - 1971. The biology of the South African rock lobster Jasus lalandii (H. Milne-Edwards). I. Development. Invest. Rep. Div. Sea Fish. S. Afr., 92: 1-70.

Turner, K., C. Gardner and R. Swain. - 2002. Onset of maturity in male southern rock lobsters Jasus edwardsii in Tasmania, Australia. Invert. Reprod. Dev., 42: 129-135.

White, G.C. and K. P. Burnham. - 1999. Program MARK: Survival estimation from populations of marked animals. Bird Study, 46 Supplement, 120-138.

Ziegler, P.E., S. Frusher, C.R. Johnson and C. Gardner. - 2002a. Catchability of the southern rock lobster Jasus edwardsii. I. Effects of sex, season and catch history. Mar. Freshwat. Res., 53: 1143-1148.

Ziegler, P.E., C.R. Johnson, S. Frusher and C. Gardner. - 2002b. Catchability of the southern rock lobster Jasus edwardsii. II. Effects of size. Mar. Freshwat. Res., 53: 1149-1159.

Scient. ed.: P. Abelló 
